\title{
Article
}

\section{Fractal art}

\section{Giudi Scotto Rosato}

\begin{abstract}
Assuming that scientific development and artistic research are genetically similar, this article shows the common need of knowledge of art and science, their dialectical and multidirectional relations and the unstable boundaries between them. The fractal art has assimilated the cognitive and perceptive changes in the realm of non-euclidean geometries and has become a precise instrument of "epistemological observation". Artistic practices materialize and communicate the laws of science, while scientific revolutions are in actual facts metaphorical revolutions.
\end{abstract}

\section{Introduction to Fractal Art}

On November $23^{\text {rd }}, 1997$ the Paris-based online art gallery Nart (http://www.nart.com), one devoted to the arts of fractal complexity, published the Manifeste fractaliste by the Groupe Fractaliste: Art et Complexité. It was to celebrate the first auction for fractal works, in cooperation with the gallery Mabel Semmler (Paris, Espace Furstenberg), which has devoted most of its exhibition areas to fractal art since the early nineties. The text was also published by the Paris-based journal Art Press. ${ }^{1}$

The Groupe Fractaliste - Art et Complexite was established in 1994 and featured some of the most prominent American and French artists of the decade, from Carlos Ginzburg to Edward Berko.

It was a diverse group, inspired by the common will to metaphorize and represent a new model of understanding of the world's morphological complexity: fractal geometry, formalized in mathematical terms by Benoît Mandelbrot in the seventies. ${ }^{2}$

Following the publication of the scientific text Les objets fractals: forme, hasard et dimensions, ${ }^{3}$ the creative and cognitive value of fractal shapes has acted as an epistemological metaphor: artists with different sensibility and education have chosen the chaotic-fractal paradigm as their creation model.

From Europe to the Americas, there have been many artists and non-artists devoted to fractal art. By "non-artists" we mean groups of scientists who, enraptured by the extraordinary aesthetic beauty of fractals, have engaged in creative research. It is worthwhile to mention the Brazilian group Asterisco Ponto Asterisco (**) - consisting of an architect, two physicists, a musician, two engineers and a mathematician - and the German Heinz-Otto Peitgen and Peter H. Richter, authors of the famous book The Beauty of Fractal. ${ }^{4}$

In America, they range from the spiritual and intimist dimension of the fractal metaphor by Edward Berko, to the "orderly" fractal ramification by Jim Long. In France, Carlos Ginzburg, Jean-Paul Agosti, Jean Letourneur, Miguel Chevalier, Jean-Claude Meynard are among the main theorists of fractal art, intent on rebuilding the public imagination according to the paradigm of the chaotic-fractal complexity. In Italy, the pace seems to be slower. There, the main protagonists are Haebel ${ }^{5}$ and Ruggero Maggi. ${ }^{6}$

Fractal art reflects a new paradigmatic orientation of culture, in a continuum in which our view of the world takes shape: it represents the reconfirmation, at creative level, of the categories of deterministic chaos and statistic distribution which regulate the interpretation of natural incidents. This way, fractal geometry becomes an interdisciplinary venture which, in the wake of infinite magnitude and infinite smallness, has engaged scientists, philosophers ${ }^{7}$ and artists. 


\section{Euclid versus Mother Nature}

In Cubism, the idea of the objective validity of reality reinforces the relation between an object and those who see it. The profound bond with reality does not disappear; however, the notion of reality is what changes. The superimposition and juxtaposition of different viewpoints creates an absolute space-time unity: the fourth dimension.

An object appears in different points of space consecutive in time; space develops not only around but also inside and through the object, thus becoming a guide and a horizon for the sense of shape of the expression. Space is no longer the common factor infinitely harmonizing all the elements of the picture, it is rather an element like all the others, present and concrete: it is not about transfiguring reality, but rather transforming its structure.

In 1913, Guillaume Apollinaire wrote in a text entitled Les peintres cubistes:

Today scholars no longer conform to the three dimensions of geometry. Painters have been lead to naturally and - as it were - intuitively cope with new possible measures of space which, in the figurative language of the moderns, are all briefly called by the name of fourth dimension.

In mathematics, like in cubist painting, objectivity is freed from its abstract elements. New fictional universes are explored, whose topological features are not to be those of the well-established Euclidean space. Shape is broken down into geometrical planes, mutually faceted. The image, represented in each constitutive element of its reality and grasped in the moment when it unfolds in visual perception, is anything but dreamlike.

The aesthetic results of fractalism are quite distant from Cubism. In addition, cubists are looking for the fourth dimension. Mathematical horizons are different yet equally original comparing with the relative validity conditions of scientific knowledge.

It is not a far-fetched hypothesis to identify a common urge in the free reconstruction of the image of an object - freed from a strictly three-dimension order - to reinforce the bond with reality: "order and disorder", "instability and deterministic chaos" fall within the definition of the fractal object as a natural object.

Thus, fractals represent a way to penetrate shape so as to identify definable and predictable trajectories beyond the diversification of contingent manifestations. The fractal work is fully immersed into the vortex of the knowableness of these complex systems, without dispersing in playful or intimistic abstractionism.

Gilles Deleuze and Félix Guattari wrote: «Abstract is not directly opposed to figurative». ${ }^{9}$ The figurative character of a work of art is not the result of a faithful reproduction of optical data, but the consequence «deriving from certain traits of the line when it takes one shape or another». ${ }^{10}$

After all, every artist - expressing themselves through shapes in which the object of the representation can be recognized more or less directly - cannot remove the issue of the visual perceptions from the observer's point of view: "A painter is also the first observer of him/herself, and everything he or she can aim at is harmony of the perceptions, not a map». ${ }^{11}$

The composition structure, a strict and classical one, of $15^{\text {th }}$-century painting includes a subjective visual experience. However, «the aim of every developed representation theory is to give subjectivism what it deserves, but without making concessions to relativism». ${ }^{12}$

A fractal-type form of expression does not circumscribe contours, does not configures rectilinear systems, nor orderly sets of points. An artist removes conventional relations between him/herself and sight, based on perspective and the customary notions of the Euclidean model: he or she builds an irregular space which each element contributes to determine as a fractus, i.e. discontinued and asymmetrical.

Such a distribution of space recalls the dimension of the abstract, of the «mutant line without exterior and interior, without shape nor bottom, without beginning nor end». ${ }^{13}$ An object having reality in itself as a foundation collapses: the external world - as opposed to the subject who thinks and learns - is no longer mediated by objective content, as a consequence of which space is perceived and represented through well-established forms.

The 'individual' is the unexpressed remainder of visual experience, the opaque background resisting the given meaning, translated into a model through encyclopedic inscription. However, fractal art cannot be reduced to transcendental subjectivism, isolated and separate essence, closed within its specificity. On the other hand, even the painting Improvisation by Wassili Kandinsky would look as an obscure and 
senseless doodle if analyzed as a model in itself, perfect and exemplary. A painting is not a transmission of shapes, but a transmission of forces acting as a stimulus for the viewer.

Abstractionism, breaking free from traditional representation systems, does not become inexpressive.

Vague, fragmented, disconnected images are not meant to recognize objects, let alone to represent them. Conversely, their purpose is to bring a phenomenon as it is to conscience, in the primary and essential condition of its existence, and to make it "happen" within conscience.

In his book Concerning the Spiritual in Art (1910), Kandinsky explains that every shape is significant as it has and takes a meaning. Therefore, each shape presents its own intrinsic content: not an objective content, but a content-force which passes on from man to man without the intermediation of the objects of common experience.

In the same perspective, Deleuze and Guattari, drawing on the considerations by Wilhelm Worringer about the gothic line, wrote: «the nomadic line that flows from abstraction presents the power of expression and not the form, repetition as power and not symmetry as form». ${ }^{14}$

Stability and the chessboard-like set-up of linear systems limit repetition through symmetry, stopping its degeneration to irregular trajectories. On the contrary, in non-linear systems (such as the fractal geometric figure), the impulse to repetition multiplies the effects of shape, by moving forward with swerves and decentralizations.

Schematism is not a feature of the living: «Everything is living, not because everything is organic and organized, yet - on the contrary - because the organism is a deviation to life». ${ }^{15}$ What follows is that Euclidean geometry does not describe the living, but it works on a mental level which postulates realities which transcend the purely phenomenal plane.

Contrarily to the empirical awareness of the irregular character of nature, the figurative model of the Euclidean space stems from a synthetic and a priori abstraction, which refers to a precise, well-defined image. From a philosophic point of view, this approach was criticized by David Hume's skepticism, whereas it found wide support in Kant's philosophy, according to which space is a necessary a priori representation.

The pure principles of intellect coincide, according to Immanuel Kant, with the general laws of nature. Therefore, the unity which is found in natural world is not intrinsic to things per se, but it is the projection of the transcendent unity (of the "I think") in the phenomenal world.

This philosophical model reinforces the foundations of Euclid's principles, making its necessary validity shift from the objective structures of being to the subjective laws (though necessary) of thought.

What are the straight lines to which Euclidean axioms apply? What is a straight line parallel to a given line? Thus, the classic geometric interpretation tackles these questions through the conceptualization of space: it justifies the postulates leaving aside empirical determinations of natural objects.

When the correspondence with phenomenal reality is established before any sensible perception, then one has to explain how one can be aprioristically certain of the validity of the axioms. The same observations, which would confirm the Euclidean character of reality, are approximate as they exclude the diversity and the asymmetry of natural forms.

«Consider three points on the surface of the Earth, e.g. the peaks of three mountains, place a telescope on each of them and measure, in degrees, the angle formed by the orientations of the telescope according to which the peaks of the other two mountains appear respectively at the centre of the lens. This way, you obtain three numbers». ${ }^{16}$ The sum of the angles of an Euclidean triangle is $180^{\circ}$. The sum of the three numbers should therefore be $180^{\circ}$. But can you be truly certain of that? And, above all, is the postulate reliable beyond any experimental verification?

In fact, the intervention of a deviation in the trajectory of a body cannot be aprioristically excluded: the real triangle does not necessarily coincide with the Euclidean one. In this respect, we recall the words pronounced by Albert Einstein in a conference on "Geometry and Experience" in 1921:

As far as the laws of mathematics refer to reality, they are not certain; and as far as they are certain, they do not refer to reality. ${ }^{17}$

Einstein demystified the absolute value traditionally attached to geometrical-mathematical axioms, riding the wave of a debate opened by Henri Poincaré. In La Science et l'Hypothèse, ${ }^{18}$ the latter vigorously claimed that Kant's thesis of Euclidean space as the only possible a priori form of sensibility and the presumption to work out geometric issues in a definitive way on an empirical basis were both in vain if they were to ascertain absolute truth. 
Experience and reason do not impose any particular geometric choice, but they guide us into the choice without forcing us; they do not show us which geometry is truer, but only which is the most convenient in terms of thought and action. Consequently, it is a question of convention.

Many different conceptual set-ups of the same observation data are always possible. No theory is sufficient on its own to derive empirical consequences: a specific experience does not contrast a specific theory, but one of the theories that have been employed in interpreting experience itself.

Fractal geometry, redeeming from a transcendental model for the representation of nature, becomes «a method to describe, calculate and reflect on forms which are irregular and fragmented, fractured and broken, from the crystal curves of snowflakes to discontinued dusts of galaxies». ${ }^{19}$

A fractal curve is a mathematical entity which has a very regular and precise (whole or fractional) numerical value: the fractal object therefore implies an organized structure, hidden below the incredible complexity of some natural shapes.

The axioms leave room to a fractal abstraction which - on the basis of Richard Taylor's research could be defined more Pollockian: ${ }^{20}$ the rules of the old idea of harmony give way to dynamic systems, simultaneously sharing order and disorder, instability and deterministic chaos, self-organization and emergence.

\section{Was Pollock a fractalist?}

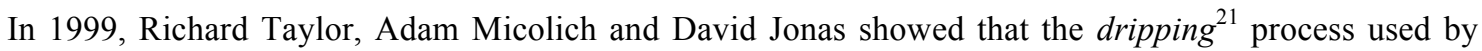
Jackson Pollock generates stochastic fractals similar to those which are found in nature: «Here we describe an analysis of Pollock's patterns which shows, first, that they are fractal, reflecting the fingerprint of nature, and, second, that the fractal dimensions increased over Pollock's career». ${ }^{22}$

It is not a scientific method, but a conscious choice to abandon traditional Euclidean-type shapes: if «an artist operates on the world only through the way he or she shapes his or her art», ${ }^{23}$ Pollock intends to represent a possible reality by using an expression method which is differently coded, of a type other than the well-established one.

Pollock starts from the paint drop he drips on canvas: not a subject and an object, not time to spend, not space to go through. The dripping technique allows him to reconstruct the conditions for a possible expression beyond any other pre-established logic. To let a painting become a natural incident, there are no rules, neither as starting assumptions nor as end results.

The visual outcome of this creative/cognitive exploration is surprising. The comparison between a localized core of trajectories from a Pollock's painting (One: Number 31) and small sections of natural shapes (snow and forest) dissolve in visual homogeneity requiring a caption to identify the work of art:

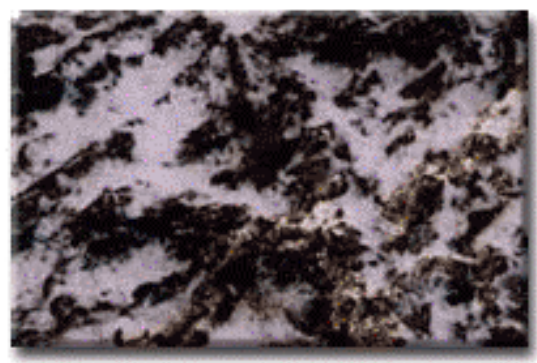

Figure 1. R. P. Taylor, A. P. Micolich, D. Jonas, Photographs of a $0.1 \mathrm{~m}$ section of snow on the ground. ${ }^{24}$ 


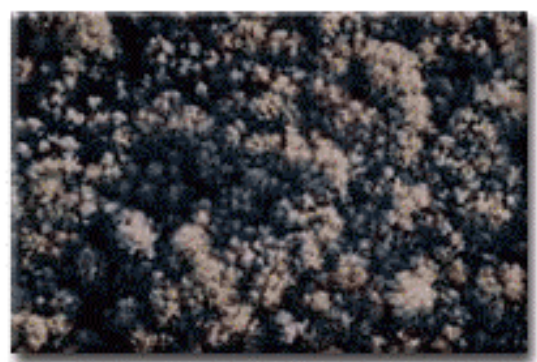

Figure 2. R.P. Taylor, A.P. Micolich, D. Jonas, Photographs of a $50 \mathrm{~m}$ section of forest. ${ }^{25}$

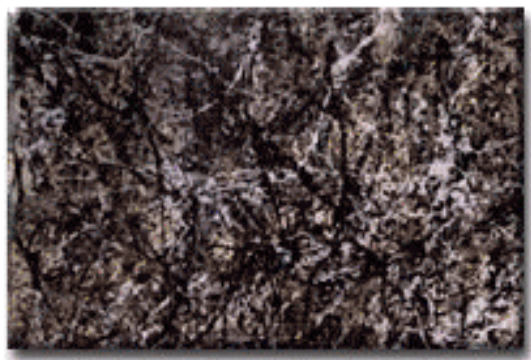

Figure 3. R.P. Taylor, A.P. Micolich, D. Jonas, Photographs of a $2.5 \mathrm{~m}$ section of Pollock’s "One: Number 31 ". ${ }^{26}$

The automatism and the spontaneity of painting - meant as a direct transposition on canvas of the vital tension of the artist - outline a vertical path, apparently chaotic. However, Pollock's abstract line does not become a way to escape reality. It is a line without spiritualistic or metaphysical alibis, sinking into an intact, biological world, in stark contrast with the precise straight lines from the transcendental abstraction of Euclidean geometry.

In other terms, Pollock's creations do not abandon shape as a basic condition of communication, yet they create a dynamic complexity where the gesture (action painting) is not left outside the mark. The paint dripping action reproduces natural disorder: forests, vibration of light, boughs, mountains, sea waves. But then, what kind of painting is this?

«Painting with the freedom of nature», ${ }^{27}$ as Eco wrote in the sixties; Painting with the freedom of fractal shapes, as we would say today.

Richard Taylor, Adam Micolich and David Jonas analyzed Pollock's paintings with a computer, scanning them through a grid of identical squared cells: the drops fallen on canvas reveal a distribution pattern for paint-filled areas and white (paintless) areas which is of an iterated type. The statistic qualities of this pattern, even when the observation scale is reduced in size, are repeated according to a specific parameter, which is given the name of fractal dimension $\mathrm{D}$ :
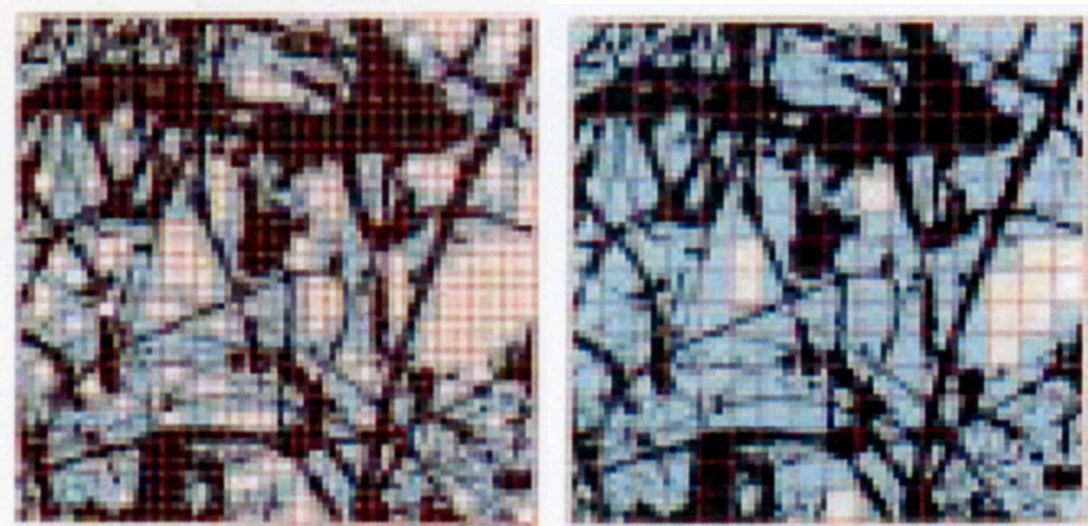

Figure 4. R.P. Taylor, Computer scan of "Autumn Rhythm" - J. Pollock, $1950{ }^{28}$ 
The dimension D quantifies the visual complexity of a fractal model: its value, in Pollock's work, is comprised between 1 and 2 . The more visual complexity thickens, the more the value $\mathrm{D}$ tends to $2 .^{29}$

The interesting aspect is not quantitative information in itself, but rather the deep bond between the D value of the fractal pigment net and its visual aspect: a formal bond, but at the same time a gestural, creative one. A bond contradicting the common opinion that Pollock's abstractionism is exclusively the result of an instant of inspiration and passion.

Taylor even demonstrated that the value of the fractal dimension $\mathrm{D}$ increased over the ten years in which the artist painted with the dripping technique, passing from $\mathrm{D}=1.1$ in 1944 to $\mathrm{D}=1.7$ in 1952 , up to $\mathrm{D}=1.9$ in a destroyed painting. Data are shown in the following graph Complexity/Year:

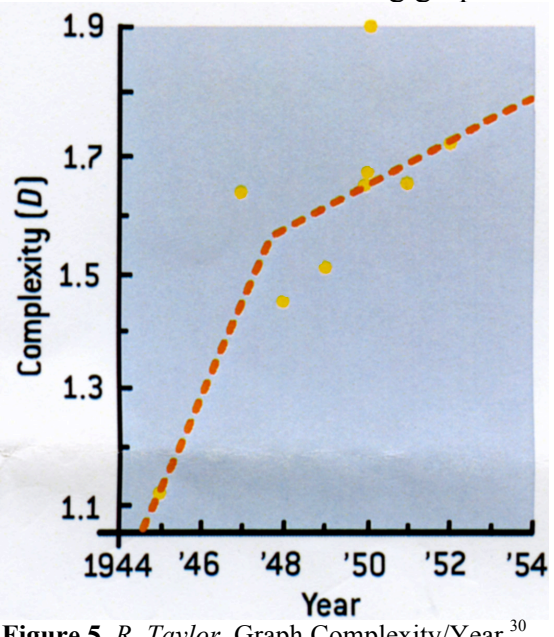

Ascertaining the fractal nature of the so-called "drip" works by Pollock might be a sterile activity, if reduced to mere scientific data. Art is not legitimated as far as it corresponds to experimentally tested knowledge. The analysis has to move onto the imagination level instead.

Although the reference level is not of a narrative type, the object represented in the picture and through the picture is build on the basis of a mental experiment unrelated to any experimental verification, as «it does not aim to draw consequences which will then have to face the present world, but rather to draw theoretical consequences to see how far one can reach». ${ }^{31}$

Pollock does not aim at a fractal representation of reality. There is not a plan behind his creative process: his tangles of marks stem from the awareness of breaking free from the pre-ordered orbit of reality and the necessity of reconstructing the primitive dialectics of nature, without the preventive guarantee of wellestablished shapes. We are the ones who attach Pollock's paintings - based on Mandelbrot's theory - a specific and identifying reference: first, there was an iconographic acknowledgement, referable to a system of "beliefs" operating as a filtering system; second, there was an attempt to empirically support the image of a possible representation of the world, through a computer test.

Each domain of knowledge, expressing a fragment of our experience through its structures, «does not express something inexpressible, rather something expressible awaiting an expression». "The expressible expresses itself in a particular domain», however it does not reduce to it, as it refers «its complete expression to a translatability in other domains which is a fundamental part of its own essence». ${ }^{32}$

Finding a fractal mark in the creative work by Pollock identifies what Eco calls primary iconism and Charles Sanders Peirce calls ground... «a mark, a quality that (no matter what reasons) is isolated and considered in itself. Who isolates it? Potentially isolable, it is isolated when a subject isolates it, in a certain respect, and then it becomes the terminus a quo of an inferential process, as it were, upwards and not downwards - i.e. towards the series of relations that bind that machine to me and my perceptive interests, not towards the series of the possible infinite breakdowns of the machine itself $\gg .^{33}$

The fractal becomes the terminus a quo of an inferential process that, from a perceptive (paradigmatic) point of view, refers Pollock's "drip" paintings to the natural fractal shape and not to the large chaotic breakdown as an end in itself. 
The fractalization process, though rooted in infinite magnitude and infinite smallness, is quantifiable in the fractional dimension D at any rate. Given two points - even very close to each other - on the sea coast, the distance between them is always infinite. However, «it does not mean that Achilles cannot cover this space in a single step in action. Achilles will cover his unit of length in a given unit of time of his». ${ }^{34}$

Infinite magnitude and infinite smallness do not dissolve in the fragmentation of the image, as they are contents in a finite area which may configure the object of an empirical intuition. Besides, Eco quotes Paolo Zellini and recalls that «the existence of an observability threshold» constitutes «a postulate both of physics and of psychology of perception». ${ }^{35}$

The fictional level on which imagination has full jurisdiction is created starting from an indivisible minimum, which cannot be broken down any further: "You can talk about the thousandth or ten thousandth part of a sand grain, but (and I would add: besides, you cannot see it - which is relevant when it comes to perception) you cannot imagine it if not in the size of the grain itself». ${ }^{36}$

Ernst H. Gombrich, debating on the impressionist viewpoint, highlights the centrality of the observer in the impressionist technique: the artist can be incomplete in some points of the visual field only because he or she is aware that the observers are able to complete the picture by themselves. ${ }^{37}$ At the same time, the scientist attempts to make a theory attainable appealing to a primary iconism from which to start for any subsequent inferences.

Still in this perspective, fractal art - as with the fractal geometric line - does not express the formal conditions starting from which an orderly system is created. It is related to the complexity of nature instead: it realizes a Pollock-like abstraction. There, what you see is not an aprioristically determined shape which is then reiterated in its details, but the shape of deterministic chaos itself: the single fragments do not constitute mechanical elements of the whole, but living organisms - and therefore dynamic and uncertain ones of a disorder, which is deterministic at any rate.

In the light of the so-called Pollock's fractals, but in general of the different works preceding the mathematical formalization of Mandlebrot and characterized by "symmetries of the elements", by "recurring structures", and "a play of scale", ${ }^{38}$ it is legitimate to wonder: «Est-il vraiment indispensable de se référer à la science physico-mathématique des systèmes dynamiques pour créer des phénomènes artistiques qui symbolisent intuitivement l'arsenal des méthodes et concepts de la fractalité mathématique?».39

\section{Can a scientific theory act as a value criterion for the work of art?}

Even art contributes to change the perception of the world of a given culture. It may be an instrument for epistemological observation able to build a cognitive paradigm of reality that is consistent and updated.

With this theoretical and analytical awareness, one should highlight that the so-called fractalist artists, who developed their creative path based on a well-considered and conscious support of the chaotic-fractal paradigm, present a cognitive approach and a visual sensibility which are strongly influenced by computer graphics.

If Mandelbrot's studies are considered as a watershed between works marked by recurring processes and deterministic chaos, the main differentiation factor is the computer visualization of the fractal object.

However, the chance to practically see a fractal object and to recognize natural shapes in it does not mark the birth of a new aesthetic theory (let alone a new scientific theory), but it flows into the continuum of code transformations. These transformations take place on the basis of culturally accepted codifications: "It would sound far-fetched to say that a painting is a set of marks recognizable like a poem. But it would be equally far-fetched to say that a painting is not a semiotic phenomenon: it rather represents the moment in which a semiotic phenomenon is born, the moment in which a code is put forward based on the remains of previous codes». ${ }^{40}$

The artistic experience of fractal forms - with or without scientific theorization - therefore experiments a new figurative semantics, through which artists free themselves from an all-engaging and toneless picture of the world, by challenging its claim to establish itself as a horizon of absolute meaning.

In this endless process of stabilization and reorganization of codes, the "post-Mandelbrot fractal art" focuses on a pre-existing description of the world (Euclidean geometry) and accelerates, as it were, the collective awareness of those changes. Likewise, fractal geometry would be unconceivable without the theoretical contribution developed by the $19^{\text {th }}$-century differential geometry and the subsequent studies by Felix Hausdorff, Abram Besicovitch, Gaston Julia. In scientific activity, discovery starts with the 
realization of an anomaly - i.e. the realization that the expectations generated by the current paradigm are not true - and goes on with the exploration of the anomaly until its complete theoretical assimilation. ${ }^{41}$

The possible sense developments in science and in art do not obviously have autonomous lives. They emerge from a more complex metaphorical reorientation of the categories of thought and vision and from concurrent developments or changes in ideological, aesthetic and perceptive spheres: these shifts involve society and more generally culture and therefore art and science as products of theirs and, at the same time, as active subjects of paradigmatic movements. Man - either scientist or artist - questions the very mechanisms meant to perceive and know the world and therefore constructively opens different contexts of sense.

For those reasons, it may be reductive to circumscribe the fractal art identity to an algorithm generating a computer image.

The computer works as a sort of microscope, providing the artist with an original standpoint to create the content of their expressive forms. Moreover, as illustrated above, not all the artists who are selfdefined as fractalists use information technology.

Fractal art is not necessarily computer art. Over-restrictive correlations belittle their identity which, on the other hand, should be sought in the vortex of knowableness and irregular harmonies: "L'art cherche à rendre visible un regard fractaliste. Il cherche à encourager le spectateur à voir et à expérimenter la fractalité qui est autour de lui, qui se retrouve dans les formes de la vie». ${ }^{42}$

Fractal art has the ability to put two traditionally separated domains into a cognitive and imaginative relation, by using the figurative form of artistic expression (coded by the fractal geometric model) as a lens to filter the complexity of reality.

Aside from any overenthusiasm, the art-science relationship should be probably understood in the sense of a dynamic complexity: well-determined yet unpredictable. There is an attempt to break free from transcendental and consolidated models and fractal art is an instrument, but also a result of this.

An original view of the world does not simply correspond to a new scientific theory, but it refers to the set of choices and instruments of an epistemological, artistic, linguistic type which structure a different way to perceive, represent and imagine the experience culturally and perceptively stored.

Thus shape is a cognitive strategy aiming at providing a new meaning or a new perspective to reality, which appears manifold as it is. This is the level where two aspects that were separate in Kant's philosophy meet: «A general theory of the a priori conditions of cognitive sensibility, and a theory of the taste judgment, with its enigmatic non-conceptual relationship between beauty and truth, which is the model for the understanding of the work of art». ${ }^{43}$

The point is that every knowledge has a cognitive function and a creative and emotional character: the objectivity of science is only an illusion, just as the work of art offers original viewpoints to build our image of the world.

In this perspective, fractal art expressions do not invoke a mystical dimension, but they exemplify the ability of structuring reality in new ways, able to highlight aspects previously disregarded or to reorganize the same codes in a different way. On the one hand, this maze-like view becomes entangled; on the other hand, it is an effective springboard to a wider and more varied exploration of knowledge and its endless character.

Translated by Massimo Caregnato

\section{Notes and references}

Groupe Les Fractalistes - Art et Complexité, Manifeste fractaliste, “Art Press”, n. 229, November 1997, pp. 28-30.

2 A fractal - from the Latin word fractus, which describes a broken and irregular stone - is a complex geometrical figure which, differently from the Euclidean model, is discontinued and fragmented. It is possible to visualize the complex geometrical shape through an algorithmic process implemented by a computer: very simple equations, processed with a computer by iterating processes, give rise to extraordinary shapes with an increasing complexity. Based on algorithms and data, the computer graphically illustrates the possible retroactive trajectories of the chaotic systems: a basic repeating "pattern", in which fractured sub-structures reveal the moment when predictability disappears.

3 B. Mandelbrot (1975), Les objets fractals: forme, hasard et dimensions, Paris, Flammarion.

4 H.-O. Peitgen e P.H. Richter (1987), La bellezza dei frattali [1986], Torino, Bollati Boringhieri.

5 Haebel - pseudonym of Antonio D'Anna - began his fractal study in the early nineties: Geometrie frattali (Studio A.E.A. Corigliano Calabro, 1990); Geometrie frattali e documentazione artisti frattalisti internazionali (Associazione culturale POIEIN - 
Napoli, 1993); Chaosmosi (Centro Luigi Di Sarro - Roma, 1998); Geometrie frattali (Centro d'Arte Il Brandale - Savona, 1998); Geometrie frattali e documentazione artisti frattalisti internazionali (Liceo Scientifico E. Majorana - Roma, 1998); Geometrie frattali (Banca del Salento - Ostia Lido, 1999); Chaosmosi (Università degli Studi di Roma - Torvergata, 1999); Geometrie frattali (CIAC M21 - Caserta, 1999); Isole (Spoleto-Arté, 2003).

6 Ruggero Maggi opens up his artistic experience to the unlimited potential of the chaos theory starting from the second half of the nineties, organizing one-man exhibitions and many fractal art shows: Ruggero Maggi - Arte Caotica (Art Now - Capua, 1996); Caos Italiano (collective exhibition by Milan Art Center - Scoglio di Quarto - Spazio Quintocortile Arte - Palazzo Nieddu del Rio di Locri, 1998); Estrada Dos Chãos (collective exhibition by Milan Art Center, MIART, 1998); Caos Italiano: De Rerum Natura (collective exhibition by Milan Art Center, Museo civico di Portogruaro, 1999); Caos Italiano: Nuove Visioni (collective exhibition by Milan Art Center, Antico Ospedale dei Battuti - Torre Scaramuccia, 1999); Caos Italiano: Risonanze Dinamiche (collective exhibition by Milan Art Center, Auditorium di S. Vito al Tagliamento, 1999); Caos: Villaggio Globale (collective exhibition by Milan Art Center, ATTIVARIA - officina culturale, Latisana, 1999); Caos - Caotica Arte Ordinata Scienza (collective exhibition by Milan Art Center, Società Umanitaria - Milano, 2000); Isole frattali (Fondazione D'Ars, Antico Palazzo della Pretura - Castell'Arquato, 2003); CAoTICA (collective exhibition by Milan Art Center, Spazio Culturale Santa Chiara di Vercelli, 2004); Ruggero Maggi - Confine Mobile (Archivio Storico del Comune di Lodi, 2004); Attrazione frattale (Premio Oscar Signorini - Fondazione d'Ars, 2006); Ruggero Maggi - Underwood (Civica Galleria d'Arte Moderna di Gallarate, 2006). The collective exhibitions, which included drawings, paintings, sculptures, videos, installations and photos, involved a number of artists. Along with Haebel and Ruggero Maggi, they included: Bruno Munari, Gianni, Marussi, Gianni D’Anna, Paolo Barlusconi, Kappa, Franca Lanna, Renata Petti, Fernardo Garbellotto, Alba Savoi, Lucio Saffaro, Carlo Cirillo, Francesco Cosentino, Marcello Diotallevi, Guido Pini, Mauro Manfredi, Angelo Caruso, Fernardo Andolcetti, Giorgio Nelva, Cosimo Cimino. Other artists directly process computer images and exhibit their works on the web: Elio Pastore, Franco Pugliese, Federico Miorello.

7 Starting from the early sixties, historians and science philosophers - from Gerard Holton to Thomas Kuhn, from Paul Feyerabend to Michel Serres - destroyed the reassuring certainties which had long been assigned to an apologetic view of science through the analysis of the so-called "paradigm" of scientific revolutions. In this climate, one of the first to deal with fractal geometry and its epistemological and cognitive implications was Michel Serres in Hermès V-Le passage du Nord-Ouest, Paris, éd. de Minuit, 1980: "Sortons, laissons-nous conduire par Benoît Mandelbrot. Le monde terraqué nous revient, grâce à lui, par immenses morceaux, le vent, l'océan, le rivage. Ce sera bientôt la fête du monde ou le retour de oublié. Voici le retour des éponges, naguère méprisées" (Michel Serres, Hermès V-Le passage du Nord-Ouest, Paris, éd. de Minuit, 1980, pp. 101 e 103).

${ }^{8}$ G. Apollinaire (2000), Les peintres cubistes, taken from M. De Micheli, Le avanguardie artistiche del Novecento, Milano, Feltrinelli, , p. 364.

9 G. Deleuze and F. Guattari (1987), Mille piani: capitalismo e schizofrenia, Roma, Istituto della Enciclopedia Italiana, p. 726.

${ }^{10}$ Ibidem.

${ }^{11}$ Ernst H. Gombrich (1985), L'immagine e l'occhio: Altri studi sulla psicologia della rappresentazione pittorica, Torino, Einaudi, p. 212.

12 Ibidem.

${ }^{13}$ G. Deleuze, F. Guattari, op. cit., p. 727.

${ }^{14}$ Ibidem.

${ }^{15}$ Ivi, p. 728

${ }^{16}$ M. Mamone Capria (1999), La crisi delle concezioni ordinarie di spazio e tempo: La teoria della relatività, in La costruzione dell 'immagine scientifica del mondo, edited by M. Mamone Capria, Napoli, La città del sole, pp. 382-383.

${ }_{17}^{17}$ A. Einstein (1958), Idee e Opinioni [1954], Milano, Schwarz, p. 254.

${ }^{18}$ H. Poincaré (1968), La Science et l'Hypothèse [1902], Parigi, Flammarion.

${ }^{19}$ J. Gleick, Caos, Milano, Biblioteca Universale Rizzoli, 2002, p. 117.

${ }^{20}$ Cfr. R.P. Taylor, A.P. Micolich, D. Jonas, Fractal analysis of Pollock's drip paintings, "Nature", CCCXCIX, 3 June 1999 , p. 422; R.P. Taylor, A.P. Micolich, D. Jonas, Fractal Expressionism, "Physics World", XII, n. 10, 1999, p. 25; R.P. Taylor, A.P. Micolich, D. Jonas, The construction of Pollock's fractal drip paintings, "Leonardo", XXXV, n. 2, 2002, pp. 203-207; R.P. Taylor, Ordine nel caos di Pollock, "Le scienze", n. 403, gennaio 2003, pp. 88-93.

${ }^{21}$ A technique implying paint dripping from above, inspired by the ritual paintings done on the sand by the Navajo people.

${ }^{22}$ R.P. Taylor, A.P. Micolich and D. Jonas, Fractal analysis of Pollock's drip paintings, cit., p. 422.

${ }^{23}$ U. Eco (1983), La definizione dell'arte [1968], Milano, Garzanti, p. 246; Cfr. P. Jachia (2008), Umberto Eco. Arte semiotica letteratura, Lecce, Manni.

${ }^{24}$ R. P. Taylor, A. P. Micolich and D. Jonas, Fractal Expressionism, cit., p. 25.

${ }^{25}$ Ibidem.

${ }^{26}$ Ibidem.

${ }^{27}$ U. Eco (1989), Opera aperta [1962], Milano, Bompiani, p. 181

${ }^{28}$ R. P. Taylor, Ordine nel caos di Pollock, cit., p. 91.

${ }^{29}$ Following are a few examples comparing the fractal dimension D from some works by Pollock and from some natural landscapes: «Pollock's painting Untitled (1945) $(\mathrm{D}=1.10)$ - clouds $(\mathrm{D}=1.3)$; Pollock's painting Untitled $(1950)(\mathrm{D}=1.89)$ - forest $(\mathrm{D}=1.89) »(\mathrm{R} . \mathrm{P}$. Taylor, Alla ricerca dell'arte frattale che riduce lo stress: da Jackson Pollock a Frank Gehry, in Matematica e Cultura 2005, edited by M. Emmer, Milano, Springer, 2005, p. 250).

${ }^{30}$ Ibidem.

${ }^{31} \mathrm{G}$. Boniolo (2005), Esperimenti mentali nella scienza e nella letteratura: una medesima struttura?, in Aa. Vv., La scienza e la parola, a cura di G. Lanzavecchia e M. Negrotti, Milano, Libri Scheiwiller, p. 183.

${ }^{32}$ C. Paolucci (2007), Da che cosa di riconosce la semiotica interpretativa?, in Aa. Vv., Studi di semiotica interpretativa, a cura di C. Paolucci, Bompiani, Milano, p. 133.

${ }^{33}$ U. Eco, La soglia e l’infinito, in Aa. Vv., Studi di semiotica interpretativa, cit., p. 170. 
${ }^{34}$ Ivi, p. 167.

${ }^{35}$ Ivi, p. 169.

${ }^{36}$ Ibidem.

${ }^{37}$ Gombrich wrote: «The impressionist technique consisting in trying to capture the fleeting view of an instant should rely twice on what I defined "the observer's part" in my book. The artist can afford incompleteness only where he or she knows the observers are able to complete the picture by themselves. [...] You can afford to leave a hand or an eye aside, buy you cannot ask the observer to identify the decorations of a dress he or she has never seen» (op. cit., p. 313).

${ }^{38}$ They are artistic experiences - Paul Klee, Marcel Duchamp, Maurits Cornelis Escher, Jackson Pollock, Katsushika Hokusai aimed at going back over the trajectories through which the perception of sensible data becomes a sight, and therefore knowability; they express an extreme precision in the epistemological research and an extremely refined ability to visualize and to translate figuratively. As they promoted the redefinition of the codes and their potentialities, these artists redefined the organization of the existing content, highlighting how the coding of the world we are used to is not the final one.

${ }^{39}$ Ivi, p. 160.

${ }^{40}$ Ivi, p. 320.

${ }^{41}$ Cfr. T. S. Kuhn (1969), La struttura delle rivoluzioni scientifiche, Torino, Einaudi.

${ }^{42}$ S. Condé, La Fractalité dans l'art contemporain cit., p. 170.

${ }^{43}$ Ibidem.

\section{Author}

Giudi Scotto Rosato was born in Pozzuoli (Naples) in 1981, studied modern literature and graduated at the university "Federico II" in Naples. In 2005 she attended an advanced course in Humanities and Literature at the institute of philosophy "Istituto Italiano per gli Studi Filosofici". From 2006 to 2008 she collaborated with the university department of literary critics as "cultrice della materia".

She publishes articles on contemporary art and culture regularly on the journal "Viatico". She has worked for a research project on "Literature and Science in the XX century", funded by the "Istituto Italiano per gli Studi Filosofici" by means of a research grant. In 2009 she attended a master course in multimedial management by "Mediaset". At present she is conducting an internship at the communication and survey agency "Euromedia Research". E-mail: giudiscotto@gmail.com.

How TO CITE: $\quad$ G.S. Rosato, Fractal art, Jcom 09(04) (2010) A01. 